Artículo

\title{
Caracterización de poblaciones de chía silvestre y cultivada
}

\author{
Alberto Calderón-Ruíz ${ }^{1 \S}$ \\ Salvador Montes-Hernández ${ }^{2}$ \\ M. Antonio García-Perea ${ }^{1}$ \\ Jorge Covarrubias Prieto ${ }^{1}$ \\ Cesar L. Aguirre-Mancilla ${ }^{1}$ \\ Juan Carlos Raya-Pérez ${ }^{1}$
}

${ }^{1}$ Tecnológico Nacional de México-Instituto Tecnológico de Roque. Carretera Celaya-Juventino Rosas km 8, Celaya, Guanajuato. CP. 38110. (markovan15@gmail.com; jocovarrubias@itroque.edu.mx; ceaguirre@itroque.edu.mx; juraya@itroque.edu.mx). ${ }^{2}$ Campo Experimental Bajío-INIFAP. Carretera Celaya-San Miguel de Allende km 6.5, Celaya, Guanajuato. CP. 38010. (montes.salvador@inifap.gob.mx).

${ }^{\S}$ Autor para correspondencia: ruizcalderonalbert@ gmail.com.

\section{Resumen}

Es un cultivo anual de ambientes templados y semicálidos con suelos arcillosos y arenosos. Existen poblaciones silvestres en México que en tiempos precolombinos permitieron seleccionar plantas con fruto más grande que no dispersara la semilla. Las variedades domesticadas, comparadas con las silvestres, tienen semillas de mayor tamaño, inflorescencia más compacta, cálices cerrados, flor más larga, dominancia apical, uniformidad en los periodos de floración y maduración. La chía contiene entre 9 y $23 \%$ de proteína, $26-41 \%$ de carbohidratos y de 30 a $33 \%$ de aceite, $40 \%$ de fibra dietética y calcio y un alto contenido de antioxidantes. Ha adquirido gran importancia porque se considera un alimento funcional. Existe consenso sobre la importancia del estudio y conservación de los recursos fitogenéticos. El objetivo de esta investigación fue caracterizar la diversidad morfológica de 31 genotipos de chía con base en las variaciones identificadas entre poblaciones silvestres y domesticadas. Se observó que la presencia de antocianinas es característica de plantas silvestres, así como la presencia de cáliz abierto, que está relacionado con la dispersión de las semillas; estas fueron más pequeñas y oscuras y sus cálices fueron cortos y se abrieron al madurar. El tamaño de la semilla y el peso de mil semillas están altamente correlacionado con el rendimiento por planta. Las plantas domesticadas presentaron cáliz cerrado, sin coloración por antocianinas, reducción de la pubescencia en la mayor parte de la planta, inflorescencia más grande, mayor número de floretes, mayor peso de semilla, mayor rendimiento. Se caracterizaron y agruparon poblaciones domesticadas, semidomesticadas y silvestres. Las silvestres presentan cáliz abierto. Las semidomesticadas son semejantes a las cultivadas pero presentan cáliz abierto. Las domesticadas tuvieron dominancia apical, mayor tamaño de espiga y cáliz cerrado.

Palabras clave: chía silvestre, cultivada, componentes principales, dendrograma, Salvia.

Recibido: agosto de 2021

Aceptado: octubre de 2021 


\section{Introducción}

La chía fue utilizada por civilizaciones precolombinas de Mesoamérica como alimento y medicina (Ayerza y Coates, 2004), es la fuente más importante, de origen no marino, de la ácidos grasos poliinsaturados (AGPINs o PUFA's en inglés) Omegas-3 y 6, proteínas, aceite y fibra, para el hombre (Baginsky et al., 2016; De Souza et al., 2015; Ullah et al., 2017). La semilla contiene entre 9 y $23 \%$ de proteína, 26-41\% de carbohidratos no fibrosos y de 30 a $33 \%$ del peso total de la semilla es aceite. En la actualidad ha adquirido gran importancia porque se considera como un alimento funcional (Olivos-Lugo et al., 2010; Oliveros y Paredes, 2013). Cahill (2005) afirma que la capacidad para dispersar la semilla, los tamaños y colores difieren según el nivel de domesticación.

Este autor menciona que existe una gran diversidad genética entre poblaciones silvestres de chía; las divergencias en el grado de domesticación se deben, probablemente, a que tiempos precolombinos se seleccionaron plantas únicas con frutos más grande y productivos. Mao et al. (2000) mencionan que la pérdida de mecanismos de dispersión se produce cuando se pierde la zona de abscisión de la espiga o de la parte de interés antropocéntrica. Por su parte, Cong et al. (2002) señalan que el efecto de gigantismo en plantas, normalmente es un carácter marcado en plantas cosechadas a mano, pero muchas veces hay efectos correlacionados en otras partes de la planta.

Los pimientos domesticados no solo tienen frutos más grandes que los silvestres, sino que también hojas, flores y semillas (Medina-Santos et al., 2019). En relación con la especie S. hispanica, Cahill (2005) describe que el sistema de polinización es autógamo en las silvestres con alta heredabilidad de características fenotípicas. Respecto a las características morfológicas y fenológicas que se han identificado en variedades domesticadas comparadas con las silvestres son: semillas de mayor tamaño, inflorescencia más compacta, cálices cerrados, flor más larga y dominancia apical, uniformidad en los periodos de floración y maduración. Hernández y Miranda (2008) encontraron como diferencias entre las poblaciones domesticadas y silvestres: flores más grandes, corolas que sobresalen del cáliz, inflorescencias más compactas debido al mayor número de verticilos y una menor distancia entre ellos, ciclo biológico más tardío y mayor tamaño de semilla.

Poblaciones de chía silvestre se encuentran en bosques de pino-encino hacia el oeste de México entre las alturas de 1400 a $2000 \mathrm{msnm}$, en la Sierra Madre Occidental, en el eje volcánico transmexicano y la Sierra Madre de Chiapas; también se encuentran en Guatemala (Cahill, 2004; Hernandez y Miranda, 2008). Ayerza y Coates (2004); Capitani et al., (2012); Loreto et al. (2013) señalan que el origen de $S$. hispanica es Mesoamérica, el abatimiento en la siembra y uso de la chía después de la conquista española sin duda propicio la pérdida de conocimiento sobre el cultivo y también de la diversidad genética de las poblaciones cultivadas. Incluso, las variedades seleccionadas en diversas partes del mundo proceden de una población recuperada y que se siembra en Acatic, Jalisco (Orozco de Rosas, comunicación personal). El objetivo de esta investigación fue caracterizar la diversidad morfológica de 31 genotipos de chía con base en las variaciones identificadas entre poblaciones silvestres y domesticadas.

\section{Materiales y métodos}

El trabajo se realizó en el Campo Experimental Bajío (CEBAJ), perteneciente al Instituto Nacional de investigaciones Forestales, Agrícolas y Pecuarias (INIFAP), ubicado en el km 6.5 de la carretera Celaya-San Miguel de Allende, Celaya, Guanajuato, en $20^{\circ} 34^{\prime} 49^{\prime \prime}$ latitud Norte y $100^{\circ} 49^{\prime} 31^{\prime}$ ' longitud oeste, a una altitud de $1768 \mathrm{~m}$. La obtención de las 31 poblaciones (Acc), fue por medio de recolección directa, adquisición con productores e intercambio institucional. 
Las semillas de las poblaciones estudiadas con fecha de recolección 2014 y 2015 se incrementaron en invernadero en el ciclo primavera-verano 2015. Con la finalidad de asegurar el establecimiento del cultivo, las plántulas se obtuvieron en invernadero, se usó sustrato tipo turba y lombricomposta estándar en una proporción de $50 \%$ (V/V) en charolas de poliestireno expandido de 200 cavidades para la germinación. El trasplante de los materiales (Acc) a campo se realizó el 24 de junio de 2016, mediante un diseño de bloques completos al azar con tres repeticiones, a una distancia de $20 \mathrm{~cm}$ entre plantas, la unidad experimental consistió en dos surcos de $5 \mathrm{~m}$ de largo por $0.8 \mathrm{~m}$ de ancho. Se realizó una aplicación foliar (Bayer, Bayfolan ${ }^{\circledR}$ ) en la etapa vegetativa (25 de agosto de 2016).

La toma de datos se realizó desde la aparición del botón floral y la caracterización de las 57 variables se hizo cuando se tenía 50\% + 1 de la floración. Se usó una regla graduada y un vernier de metal para las variables cuantitativas. Las cualitativas se basaron en el descriptor de la UPOV, caracterizando tres plantas en cada repetición. La prueba de germinación se realizó a, temperatura constante de $25^{\circ} \mathrm{C}$, sobre papel con cuatro repeticiones de 50 semillas (Rovati et al., 2009). Para estimar la velocidad de germinación se realizó el conteo cada 12 h, durante 96 h. Con los datos obtenidos se realizó una prueba de valores atípicos en donde se eliminaron todas aquellas que registraron el mismo valor, por lo que se entiende que ese carácter evaluado no mostró diferencias entre las poblaciones caracterizadas. Los datos se corrieron en el Software XLSTAT versión 2017.02 en paquete Excel Office versión 15.3.

\section{Resultados}

El porcentaje de germinación a las 96 horas en todas las poblaciones fue mayor al 80\%. Estos resultados concuerdan con Cahill y Provance (2002), quienes señalan que las poblaciones silvestres y domesticadas tienen un buen porcentaje de germinación; en las silvestres el periodo de germinación se extendió hasta diez días para que la semilla germinara. La variable altura está altamente correlacionada con la densidad de brotes y el número de espigas, Por lo que, entre más alta sea la planta, la densidad de brotes es mayor, al igual el número de espigas, lo cual concuerda con Sosa et al. (2016) (Cuadro 1).

Cuadro 1. Análisis conjunto de las correlaciones y de componentes principales de las 57 variables evaluadas e identificación de valores atípicos de las variables medidas.

\begin{tabular}{|c|c|c|c|c|c|c|c|}
\hline \multirow[t]{2}{*}{ EDP } & \multirow[t]{2}{*}{ Variables } & \multicolumn{3}{|c|}{$\begin{array}{c}\text { Correlaciones entre las } \\
\text { variables y los componentes }\end{array}$} & \multicolumn{3}{|c|}{$\begin{array}{c}\text { Cosenos cuadrados } \\
\text { de las variables }\end{array}$} \\
\hline & & CP1 & $\mathrm{CP} 2$ & CP3 & CP1 & $\mathrm{CP} 2$ & CP3 \\
\hline \multirow[t]{3}{*}{ Planta } & Hábito de crecimiento & 0 & 0 & 0 & 0 & 0 & 0 \\
\hline & Altura $(\mathrm{cm})$ & -0.212 & 0.113 & 0.583 & 0.045 & 0.013 & 0.34 \\
\hline & Anchura (cm) & 0.106 & -0.182 & 0.215 & 0.011 & 0.033 & 0.046 \\
\hline \multirow[t]{3}{*}{ Tallo } & Densidad de brotes & -0.046 & 0.074 & 0.482 & 0.002 & 0.005 & 0.232 \\
\hline & Coloración de antocianina & -0.544 & 0.068 & 0.129 & 0.296 & 0.005 & 0.017 \\
\hline & Pubescencia & -0.699 & 0.142 & -0.04 & 0.489 & 0.02 & 0.002 \\
\hline \multirow[t]{3}{*}{ Hoja } & Longitud del pecíolo (mm) & 0.555 & 0.042 & 0.031 & 0.308 & 0.002 & 0.001 \\
\hline & Longitud de la lámina (mm) & 0.523 & -0.139 & -0.015 & 0.273 & 0.019 & 0 \\
\hline & Anchura de la lámina & 0.57 & -0.451 & -0.267 & 0.324 & 0.203 & 0.071 \\
\hline
\end{tabular}




\begin{tabular}{|c|c|c|c|c|c|c|c|}
\hline \multirow[t]{2}{*}{ EDP } & \multirow[t]{2}{*}{ Variables } & \multicolumn{3}{|c|}{$\begin{array}{c}\text { Correlaciones entre las } \\
\text { variables y los componentes }\end{array}$} & \multicolumn{3}{|c|}{$\begin{array}{c}\text { Cosenos cuadrados } \\
\text { de las variables }\end{array}$} \\
\hline & & $\mathrm{CP} 1$ & $\mathrm{CP} 2$ & $\mathrm{CP} 3$ & $\mathrm{CP} 1$ & $\mathrm{CP} 2$ & $\mathrm{CP} 3$ \\
\hline & Relación largo/ancho de la lámina & 0.054 & 0.621 & 0.471 & 0.003 & 0.385 & 0.222 \\
\hline & $\begin{array}{l}\text { Posición de la parte más ancha de } \\
\text { la lámina }\end{array}$ & 0.256 & -0.168 & 0.073 & 0.066 & 0.028 & 0.005 \\
\hline & Forma del ápice de la lámina & -0.377 & -0.552 & -0.21 & 0.142 & 0.305 & 0.044 \\
\hline & Forma de la base de la lámina & 0.018 & -0.178 & -0.433 & 0 & 0.032 & 0.187 \\
\hline & $\begin{array}{l}\text { Color principal de la parte superior } \\
\text { de la lámina }\end{array}$ & -0.089 & -0.257 & -0.243 & 0.008 & 0.066 & 0.059 \\
\hline & Variegación de color en la lámina & 0 & 0 & 0 & 0 & 0 & 0 \\
\hline & $\begin{array}{c}\text { Distribución de la variegación de } \\
\text { la lámina }\end{array}$ & 0.26 & -0.484 & -0.473 & 0.068 & 0.234 & 0.224 \\
\hline & $\begin{array}{c}\text { Coloración de la variegación en la } \\
\text { lámina }\end{array}$ & 0.26 & -0.484 & -0.473 & 0.068 & 0.234 & 0.224 \\
\hline & $\begin{array}{c}\text { Pubescencia en la parte superior } \\
\text { de la lámina }\end{array}$ & -0.546 & -0.146 & 0.151 & 0.298 & 0.021 & 0.023 \\
\hline & Rugosidad en la lámina & -0.217 & -0.278 & -0.003 & 0.047 & 0.077 & 0 \\
\hline & Brillo de la lámina & -0.506 & -0.071 & -0.017 & 0.256 & 0.005 & 0 \\
\hline & $\begin{array}{c}\text { Incisiones en el margen de la } \\
\text { lámina }\end{array}$ & -0.154 & 0.171 & -0.227 & 0.024 & 0.029 & 0.051 \\
\hline & $\begin{array}{c}\text { Ondulación en el margen de la } \\
\text { lámina }\end{array}$ & 0.365 & 0.481 & 0.396 & 0.133 & 0.231 & 0.156 \\
\hline \multirow[t]{5}{*}{ Inflorescencia } & $\begin{array}{l}\text { Longitud de la inflorescencia } \\
\qquad(\mathrm{mm})\end{array}$ & 0.672 & -0.160 & 0.06 & 0.452 & 0.026 & 0.004 \\
\hline & Longitud de entrenudo (mm) & 0.721 & 0.181 & 0.123 & 0.52 & 0.033 & 0.015 \\
\hline & Número de floretes & 0.428 & -0.146 & 0.186 & 0.184 & 0.021 & 0.035 \\
\hline & Número de ramas laterales & 0.361 & -0.279 & -0.236 & 0.13 & 0.078 & 0.056 \\
\hline & Posición de la punta & -0.342 & 0.23 & -0.002 & 0.117 & 0.053 & 0 \\
\hline \multirow[t]{3}{*}{ Bráctea } & Persistencia & 0.47 & 0.057 & 0.241 & 0.22 & 0.003 & 0.058 \\
\hline & Longitud (mm) & 0.596 & -0.192 & -0.133 & 0.355 & 0.037 & 0.018 \\
\hline & Color principal del lado exterior & -0.33 & -0.020 & 0.022 & 0.109 & 0 & 0 \\
\hline \multirow[t]{3}{*}{ Cáliz } & Longitud del cáliz (mm) & 0.557 & -0.265 & -0.133 & 0.311 & 0.07 & 0.018 \\
\hline & Color principal del lado exterior & 0.304 & -0.037 & 0.268 & 0.092 & 0.001 & 0.072 \\
\hline & Pubescencia del lado exterior & -0.477 & 0.495 & -0.037 & 0.228 & 0.245 & 0.001 \\
\hline \multirow[t]{3}{*}{ Corola } & Longitud de la corola & 0.851 & -0.169 & -0.269 & 0.724 & 0.029 & 0.072 \\
\hline & Longitud del tubo coloral (mm) & 0.786 & -0.093 & 0.079 & 0.618 & 0.009 & 0.006 \\
\hline & $\begin{array}{l}\text { Color principal del lado exterior } \\
\text { del tubo coloral }\end{array}$ & 0.086 & -0.364 & 0.443 & 0.007 & 0.133 & 0.196 \\
\hline \multirow[t]{3}{*}{ Labio superior } & Color principal del lado exterior & 0.026 & -0.553 & 0.653 & 0.001 & 0.306 & 0.426 \\
\hline & $\begin{array}{c}\text { Color secundario de la cara } \\
\text { exterior }\end{array}$ & -0.469 & -0.437 & -0.298 & 0.22 & 0.191 & 0.089 \\
\hline & Pubescencia en el lado exterior & -0.364 & 0.440 & -0.131 & 0.133 & 0.194 & 0.017 \\
\hline
\end{tabular}




\begin{tabular}{|c|c|c|c|c|c|c|c|}
\hline \multirow[t]{2}{*}{ EDP } & \multirow[t]{2}{*}{ Variables } & \multicolumn{3}{|c|}{$\begin{array}{c}\text { Correlaciones entre las } \\
\text { variables y los componentes }\end{array}$} & \multicolumn{3}{|c|}{$\begin{array}{c}\text { Cosenos cuadrados } \\
\text { de las variables } \\
\end{array}$} \\
\hline & & CP1 & $\mathrm{CP} 2$ & CP3 & CP1 & $\mathrm{CP} 2$ & CP3 \\
\hline \multirow[t]{6}{*}{ Labio inferior } & Ancho del labio inferior (mm) & 0.683 & 0.231 & 0.363 & 0.467 & 0.053 & 0.132 \\
\hline & Posición (relación tubo coloral) & -0.056 & -0.615 & 0.163 & 0.003 & 0.378 & 0.027 \\
\hline & Color principal de la cara interna & -0.165 & -0.22 & 0.876 & 0.027 & 0.048 & 0.767 \\
\hline & Color secundario de la cara interna & -0.128 & -0.597 & 0.632 & 0.016 & 0.356 & 0.399 \\
\hline & $\begin{array}{l}\text { Distribución del color secundario } \\
\text { de la cara interna }\end{array}$ & -0.128 & -0.597 & 0.632 & 0.016 & 0.356 & 0.399 \\
\hline & Ondulación en el margen & 0.305 & -0.118 & 0.078 & 0.093 & 0.014 & 0.006 \\
\hline \multirow[t]{6}{*}{ Semilla } & Tamaño & 0.279 & -0.474 & -0.234 & 0.078 & 0.224 & 0.055 \\
\hline & Número de colores & -0.41 & -0.592 & 0.189 & 0.168 & 0.351 & 0.036 \\
\hline & Color principal (superficie mayor) & -0.324 & -0.528 & 0.023 & 0.105 & 0.279 & 0.001 \\
\hline & Color secundario & 0.096 & 0.048 & -0.037 & 0.009 & 0.002 & 0.001 \\
\hline & Distribución del color secundario & -0.330 & -0.592 & 0.218 & 0.109 & 0.351 & 0.047 \\
\hline & Peso de 1000 semillas & 0.317 & -0.48 & -0.277 & 0.101 & 0.231 & 0.077 \\
\hline \multirow[t]{2}{*}{ Otras } & Tipo de cáliz & -0.642 & 0.17 & 0.127 & 0.412 & 0.029 & 0.016 \\
\hline & Colores de semillas en accesión & -0.55 & -0.365 & 0.127 & 0.303 & 0.133 & 0.016 \\
\hline \multirow{4}{*}{$\begin{array}{l}\text { Caracteres } \\
\text { agronómicos }\end{array}$} & Rendimiento por planta & 0.613 & -0.041 & 0.326 & 0.376 & 0.002 & 0.107 \\
\hline & Número de espigas & 0.22 & -0.129 & 0.462 & 0.049 & 0.017 & 0.214 \\
\hline & Botón floral (días) & -0.792 & -0.251 & -0.163 & 0.628 & 0.063 & 0.027 \\
\hline & Floración (días) & -0.794 & -0.25 & -0.168 & 0.631 & 0.063 & 0.028 \\
\hline \multirow{3}{*}{$\begin{array}{l}\text { Análisis de } \\
\text { componentes } \\
\text { principales }\end{array}$} & Valor propio & 10.872 & 6.327 & 5.34 & & & \\
\hline & Variabilidad (\%) & 19.768 & 11.503 & 9.709 & & & \\
\hline & (\%) acumulado & 19.768 & 31.271 & 40.98 & & & \\
\hline
\end{tabular}

Los valores en negrita para cada variable corresponden al componente principal para el cual el coseno cuadrado es el mayor y por lo tanto, son las de mayor correlación negativa o positiva; EDP= estructura de la planta.

La presencia de antocianinas esta correlacionada con el tipo de cáliz (abierto) y el tiempo que le tomó llegar a floración (tardío), las plantas con presencia de antocianinas son característico de plantas silvestres, así como la presencia de cáliz abierto, que está relacionado con la dispersión de las semillas (Cahill, 2005). La pubescencia del tallo se correlacionó con la pubescencia adaxial de la hoja, esta característica fue reportada por Fernald (1907) en una descripción de variedades de chía, la pubescencia también se correlacionó con el tipo de cáliz abierto y el retraso en el inicio de la emisión del botón floral, por lo que las plantas con estas características fueron más tardías (Cuadro 1).

La longitud de la inflorescencia estuvo altamente correlacionada con la longitud de entrenudos, el número de floretes, número de ramas laterales, longitud de la bráctea, longitud de la corola, longitud del tubo de la corola, ancho del labio superior y el rendimiento por planta, lo que concuerda con los resultados de Hernández y Miranda (2008); Sosa et al. (2016) (Cuadro 1). 
El tamaño de la semilla y el peso de mil semillas están altamente correlacionado con el rendimiento por planta (Cahill y Provance, 2002; Cahill, 2005; Cahill y Ehdaie, 2005; Hernández y Miranda, 2008; Sosa et al., 2016b). Las características que difirieron entre poblaciones silvestres y domesticadas fueron: cáliz abierto, coloración de antocianinas, pubescencia en la mayor parte de la planta, reducción de la inflorescencia, menor número de floretes, menor peso de semilla, menor rendimiento. Las plantas domesticadas presentaron cáliz cerrado, sin coloración por antocianinas, reducción de la pubescencia en la mayor parte de la planta, inflorescencia más grande, mayor número de floretes, mayor peso de semilla, mayor rendimiento (Cuadro 2).

Cuadro 2. Las características que difirieron entre poblaciones silvestres y domesticadas.

\begin{tabular}{|c|c|c|c|c|c|}
\hline EDP & Variable & Mínimo & Máximo & Media & $\mathrm{DE}$ \\
\hline \multirow[t]{3}{*}{ Planta } & Altura $(\mathrm{cm})$ & 86 & 151 & 128.8 & 16.44 \\
\hline & Anchura $(\mathrm{cm})$ & 40 & 121.85 & 62.91 & 14.91 \\
\hline & Densidad de brotes & 20 & 30.6 & 24.62 & 2.55 \\
\hline \multirow[t]{2}{*}{ Tallo } & Coloración de antocianina & 1 & 4 & 1.47 & 0.86 \\
\hline & Pubescencia & 1 & 4 & 1.97 & 0.96 \\
\hline Hoja & Pubescencia en la parte superior de la lámina & 1 & 3 & 1.73 & 0.64 \\
\hline \multirow[t]{4}{*}{ Inflorescencia } & Longitud de la inflorescencia (mm) & 6.66 & 13.6 & 9.55 & 1.79 \\
\hline & Longitud de entrenudo (mm) & 5.69 & 10.9 & 7.74 & 1.37 \\
\hline & Número de floretes & 9.40 & 16.67 & 12.35 & 1.64 \\
\hline & Número de ramas laterales & 14.67 & 26.5 & 19.5 & 2.62 \\
\hline Bráctea & Longitud (mm) & 7.85 & 11.85 & 9.79 & 0.98 \\
\hline \multirow[t]{2}{*}{ Cáliz } & Longitud del cáliz (mm) & 7.13 & 9.62 & 8.17 & 0.63 \\
\hline & Pubescencia del lado exterior & 2 & 4 & 3.17 & 0.46 \\
\hline \multirow[t]{2}{*}{ Corola } & Longitud de la corola & 8.86 & 15.27 & 11.13 & 1.35 \\
\hline & longitud del tubo de la corola (mm) & 7.29 & 11.05 & 8.67 & 0.78 \\
\hline Labio inferior & Ancho del labio inferior (mm) & 3.95 & 6.55 & 5.1 & 0.69 \\
\hline \multirow[t]{6}{*}{ Semillas } & Tamaño & 3 & 7 & 4.73 & 1.72 \\
\hline & Número de colores & 5 & 7 & 6.73 & 0.69 \\
\hline & Color principal (superficie mayor) & 1 & 5 & 2.83 & 1.31 \\
\hline & Color secundario & 1 & 5 & 3.13 & 1.14 \\
\hline & Distribución del color secundario & 3 & 7 & 5.73 & 1.43 \\
\hline & Peso de 1000 semillas & 0.79 & 1.83 & 1.21 & 0.23 \\
\hline \multirow[t]{2}{*}{ Otras } & Tipo de cáliz & 1 & 9 & 3.4 & 3.73 \\
\hline & Colores de semillas en accesión & 1 & 9 & 6.73 & 2.72 \\
\hline \multirow{4}{*}{$\begin{array}{l}\text { Características } \\
\text { Agronómicas }\end{array}$} & Rendimiento por planta (g) & 8.2 & 47.13 & 26.48 & 11.45 \\
\hline & Número de espigas & 29.5 & 147 & 75.16 & 25.5 \\
\hline & Botón floral (días) & 123 & 171 & 145.53 & 12.18 \\
\hline & Floración (días) & 141 & 186 & 160.67 & 11.99 \\
\hline
\end{tabular}

$\mathrm{EDP}=$ estructura de la planta; $\mathrm{DE}=$ desviación estándar. 
El CP1 contribuyó con $29.55 \%$ de la variación y entre las variables que contribuyeron con mayor proporción se encuentran: coloración de antocianinas y pubescencia del tallo, pubescencia en la hoja, longitud de la inflorescencia y su entrenudo, la longitud de la bráctea y cáliz, la longitud del tubo de la corola, el ancho del labio inferior, tipo de cáliz, colores de semillas en accesión, el rendimiento por planta, días a inicio del botón floral y días a inicio de la floración (Cuadro 3).

Cuadro 3. Valores propios de los componentes principales.

\begin{tabular}{ccccccccc}
\hline Componentes & CP1 & CP2 & CP3 & CP4 & CP5 & CP6 & CP7 & CP8 \\
\hline Valor propio & 8.275 & 3.29 & 2.633 & 2.165 & 1.707 & 1.571 & 1.389 & 1.189 \\
Variabilidad (\%) & 29.552 & 11.75 & 9.402 & 7.732 & 6.095 & 5.61 & 4.961 & 4.248 \\
(\%) acumulado & 29.552 & 41.302 & 50.704 & 58.436 & 64.532 & 70.141 & 75.102 & 79.35 \\
\hline
\end{tabular}

El CP2 explicó $11.75 \%$ y las variables que se le atribuyeron mayor peso fueron: ancho de la planta, tamaño de semilla, número de colores en la semilla y color principal y el patrón del color secundario en la semilla. El CP3 aportó 9.4\% y las variables importantes para este componente fueron la densidad de brotes y el peso de mil semillas. Estos tres componentes explican $50.7 \%$ de la variabilidad total obtenida. La proporción de la varianza explicada con un bajo número de componentes nos permite una mejor interpretación en este tipo de análisis (Cuadro 3).

En el dendrograma (Figura 1) el grupo A está dado por la integración de las poblaciones (P, K, L, H, O, I, E, DD, D, FF, BB, GG, II, y B), este grupo se encontraron poblaciones con características de tipo silvestres y domesticadas y fueron semejantes fenológicamente. Las poblaciones $\mathrm{P}$ y $\mathrm{K}$ mostraron cáliz abierto y toda la planta presentó pubescencia abundante. Las demás poblaciones presentaron coloración de antocianinas y una reducción de la pubescencia, hasta mostrar el cierre total de cáliz en las poblaciones B, DD, D, FF, GG. En este grupo con las 28 variables evaluadas no se pudo contrastar, por lo que se dedujo que están muy emparentadas (Figura 1).

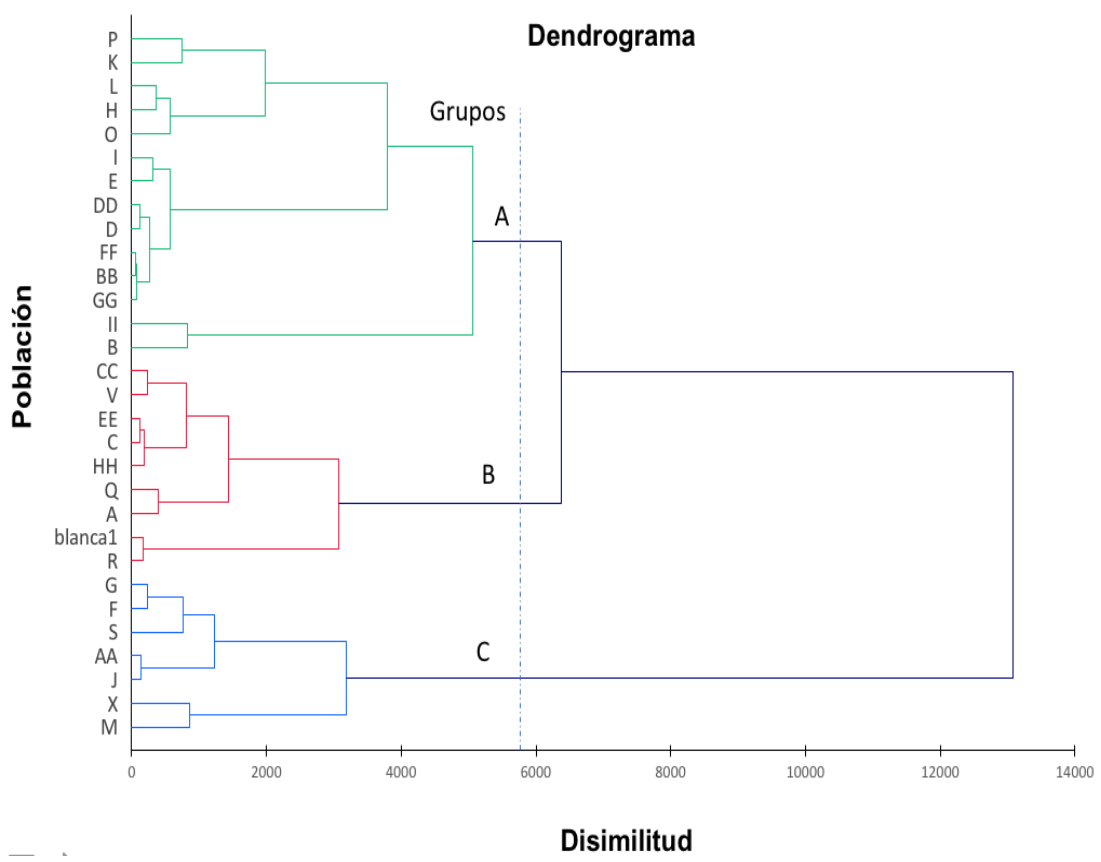

Figura 1. Dendrograma de 30 poblaciones de chía mediante 28 características morfológicas. 
Se aprecian tres grandes grupos (Figura 1). El grupo B, conformado por las poblaciones CC, V, $\mathrm{EE}, \mathrm{C}, \mathrm{HH}, \mathrm{Q}$, A, blanca 1 y R presentaron características propias de las poblaciones domesticadas, como el cierre de cáliz, disminución de la pubescencia e inflorescencia más grande. El grupo C constituido por: G, F, S, AA, J, X y M, sólo las poblaciones G y X presentaron cáliz abierto, y el resto presentó características de plantas domesticadas.

\section{Discusión}

Las plantas silvestres presentaron semillas pequeñas y oscuras y sus cálices fueron cortos y al madurar se abrieron para la dispersión de la semilla mediante el movimiento debido al efecto del viento o los animales, lo que concuerda con Cahill (2005). Las plantas silvestres tuvieron un menor número de verticilos al compararse con las cultivadas; la separación de los floretes es más conspicua, dando como resultado espigas poco compactas y flor más pequeña, como lo reportan Cahill y Provance (2002).

Las poblaciones silvestres expresaron un ligero tono de coloración de antocianinas en tallos y cálices; se ha observado que cuando una planta sufre estrés por daño ambiental, como vientos fuertes, presenta coloración intensa en los tallos. Las plantas domesticadas tienen cáliz cerrado, semilla grande y poca pubescencia en el cáliz. El cáliz cerrado previene la dispersión de la semilla, por lo que la supervivencia de la especie depende del ser humano, criterio que se identifica como característica de la domesticación en plantas. En las poblaciones silvestres no se presentó el cáliz cerrado, algo también observado por Harlan (1992). Sin duda el cáliz cerrado se seleccionó durante el proceso de domesticación.

De acuerdo con Cahill y Provance (2002), el cáliz cerrado es un carácter recesivo y el gen o genes que controlan este rasgo posiblemente tienen patrones de expresión que son influenciados por el ambiente. La chía domesticada de Guatemala, Nicaragua y el Salvador mostró un aumento en la densidad y la longitud de la pubescencia del cáliz en comparación con las silvestres (Cahill, 2005). Los genotipos de Nicaragua expresaron estos rasgos y fueron uno de los materiales más tardíos. El aumento en longitud y densidad de la pubescencia en cáliz se asocia con la adaptación a un ambiente con mayor humedad, ya que, en ausencia de la pubescencia, los cálices secos (maduros) absorben agua de lluvia provocando que las semillas se hidraten y liberen mucilago (fibra soluble) lo que resulta en un revestimiento pegajoso que se endurece afectando la propagación de la semilla.

En la chía de México no se presenta comúnmente este problema, pero en zonas con mayor humedad, como Nicaragua, se requiere protección contra la precipitación pluvial (Cahill, 2005). Las variedades domesticadas también presentaron una inflorescencia compacta, definida por un pequeño espacio entre los glomérulos y el número de flores por verticilo. Las poblaciones silvestres tienen gran variación con respecto a este rasgo. La inflorescencia más larga incrementa el rendimiento, pero este carácter siempre aparece junto con la dominancia apical, de modo que sólo la inflorescencia más cercana al ápice aumenta de longitud y las ramas secundarias con sus respectivas inflorescencias permanecen normales o con ligeras atrofias (Cahill, 2005).

Las variedades domesticadas se encuentran en el estado de Jalisco y en el Valles Centrales de México, produjeron más pigmentación por antocianinas en los tallos y cálices. Los tallos tuvieron un patrón púrpura interrumpido que se extendió hasta el cáliz, algunas variedades poseen cálices 
púrpura puros, mientras que en otros la pigmentación sólo apareció en la mitad de la parte exterior de cada cáliz. Maduran al mismo tiempo, las hojas senescen y se caen dejando sólo el tallo y las inflorescencias. La falta de follaje facilita la cosecha, particularmente si se realiza de forma mecánica (Cahill, 2005).

\section{Conclusiones}

La caracterización de las poblaciones de chía permitió diferenciar entre las poblaciones silvestres, semidomesticadas y domesticadas. Las silvestres se caracterizaron por presentar cáliz abierto, coloración por antocianinas en el tallo, pubescencia en la hoja, no presentaron dominancia apical. En el estado de semidomesticación, toda la estructura de la planta es semejante a las cultivadas y presentó coloración por antocianinas estriada en tallos con un cáliz abierto semejante a las silvestres. Por otro lado, las poblaciones domesticadas presentaron dominancia apical, mayor tamaño de espiga, cáliz cerrado y coloración en tallo. El tamaño de la semilla de las poblaciones domesticadas fue mayor que en las silvestres, lo que confiere mayor productividad en las primeras.

\section{Literatura citada}

Ayerza, R. and Coates, W. 2004. Composition of chia (Salvia hispanica) grown in six tropical and subtropical ecosystems of South America. Tropical Sci. 44(3):131-135. https://doi.org/ $10.1002 /$ ts. 154 .

Baginsky, C.; Arenas, J.; Escobar, H.; Garrido, M.; Valero, N.; Tello, D. and Silva, H. 2016. Growth and yield of chia (Salvia hispanica L.) in the mediterranean and desert climates of chile. Chil. J. Agric. Res. 76(3):255-264. https://doi.org/10.4067/S0718-58392016000 300001.

Cahill, J. P. 2004. Genetic diversity among varieties of chia (Salvia hispanica L.). Genetic resources and crop evolution. 51(7):773-781. https://doi.org/10.1023/B:GRES.00000 34583.20407.80.

Cahill, J. P. 2005. Human selection and domestication of chia (Salvia hispanica L.). J. Ethnobiol. 25(2):155-174. https://doi.org/10.2993/0278-0771.

Cahill, J. P. and Ehdaie, B. 2005. Variation and heritability of seed mass in chia (Salvia hispanica L.). Genetic resources and crop evolution. 52(2):201-207. https://doi.org/10.1007/s10722003-5122-9.

Cahill, J. P. and Provance, M. C. 2002. Genetics of qualitative traits in domesticated chia (Salvia hispanica L.). J. Hered. 93(1):52-55. https://doi.org/10.1093/jhered/93.1.52.

Capitani, M. I.; Spotorno, V.; Nolasco, S. M. and Tomás, M. C. 2012. Physicochemical and functional characterization of by-products from chia (Salvia hispanica L.) seeds of Argentina. LWT - Food Sci. Technol. 45(1):94-102. https://doi.org/10.1016/j.lwt.2011. 07.012.

Cong, B.; Liu, J. and Tanksley, S. 2002. Natural alleles at a tomato fruit size quantitative trait locus differ by heterochronic regulatory mutations. Proceedings of the national academy of Sciences of the United States of America. 99(21):13606-11. https://doi.org/10.1073/pnas. 172520999.

De-Souza, F. C.; De-Sousa, F.; Espirito, G.; Da-Silva, S. and Rosa, G. 2015. Effect of chia seed (Salvia hispanica L.) consumption on cardiovascular risk factors in humans: a systematic review. Nutrición Hospitalaria. 32(5):1909-1918. https://doi.org/10.3305/nh.2015. 32.5.9394 retrieved from http://www.redalyc.org/articulo.oa?id=85622739007\%0ACómo. 
Fernald, M. L. 1907. Diagnoses of new spermatophytes from Mexico. Proceedings of the American Academy of Arts and Sciences. American Academy of Arts and Sciences. https://doi.org/ http://www.jstor.org/stable/20022302. 43(2):(61-68).

Harlan, J. R. 1992. Grass evolution and domestication. In C. U. Press. (Ed.). Origins and processes of domestication. In: Chapma, G. P (Ed.). Cambridge University Press. 156-175 pp.

Hernández, G. A. y Miranda, C. S. 2008. Caracterización morfológica de chía (Salvia hispanica). Rev. Fitotec. Mex. 31(2):105-113. https://doi.org/0187-7380.

Loreto, M. A.; Cobos, A.; Diaz, O. and Aguilera, J. M. 2013. Chia Seed (Salvia hispanica L.): an ancient grain and a new functional food. Food Reviews Inter. 29(4):394-408. https://doi.org/10.1080/87559129.2013.818014.

Mao, L.; Begum, D.; Chuang, H. W.; Budiman, M. A.; Szymkowiak, E. J.; Irish, E. E. and Wing, R. A. 2000. JOINTLESS is a MADS-box gene controlling tomato flower abscission zone development. Nature. 406(6798):910-913. https://doi.org/10.1038/35022611.

Medina-Santos, L.C.; Covarrubias-Prieto, J.; Iturriaga, G.; Ramírez-Pimentel, J. G. y Raya-Pérez, J. C. 2019. Caracterización de colectas de chía de la región occidental de México. Rev. Mex. Cienc. Agríc. 10(8):1837-1848.

Oliveros, S. M. R. and Paredes, L. O. 2013. Isolation and characterization of proteins from chia seeds (Salvia hispanica L.). J. Agric. Food Chem. 61(1):193-201. https://doi.org/10.1021/ jf3034978.

Olivos-Lugo, B. L, Valdivia-López, M. Á. and Tecante, A. 2010. Thermal and physicochemical properties and nutritional value of the protein fraction of Mexican chia seed (Salvia hispanica L.). Food Sci. Technol. Inter. 16(1):89-96. https://doi.org/10.1177/10820 13209353087.

Rovati, A.; Escobar, E. y Prado, C. 2009. Metodología alternativa para evaluar la calidad de la semilla de chía (Salvia hispanica L.) en Tucumán, R. Argentina. EEAOC-Avance agroindustrial. 33(3):44-46.

Sosa, B. A.; Ruiz, I. G.; Miranda, C.; Gordillo, S.; Westh, H. and Mendoza, G. 2016 b. Agronomic and physiological parameters related to seed yield of white chia (Salvia hispanica L.). Acta Fitogenética. Sociedad Mexicana de Fitogénetica, AC. 3(1):31-37.

Ullah, R.; Nadeem, M. and Imran, M. 2017. Omega-3 fatty acids and oxidative stability of ice cream supplemented with olein fraction of chia (Salvia hispanica L.) oil. Lipids in health and disease, 16(1):1-8. https://doi.org/10.1186/s12944-017-0420-y.

XLSTAT. 2017. XLSTAT Software. Version. 5.02. Copyright addinsoft 1995-2017. http://www.xlstat.com. 2017. 